\title{
OS DIREITOS HUMANOS E A CULTURA DA PAZ NA PREVENÇÃO DO BULLYING ESCOLAR NA INFÂNCIA
}

\section{HUMAN RIGHTS AND THE CULTURE OF PEACE IN THE PREVENTION OF SCHOOL BULLYING IN CHILDREN}

\author{
Michelle Popenga Geraim Monteiro \\ Araci Asinelli-Luz
}

\begin{abstract}
RESUMO
$\mathrm{O}$ artigo tem por objetivo destacar os direitos humanos como estatuto ético para a prevenção do bullying escolar na infância, na perspectiva da Cultura da Paz. Inserese na discussão do reconhecimento do bullying enquanto violência escolar a partir da concepção de crianças do $5^{\circ}$ ano do Ensino Fundamental sobre o fenômeno. A discussão teórica se fundamenta no diálogo entre diferentes autores tais como Fante (2005), Lopes Neto (2005; 2011); Monteiro (2017), Salles Filho (2016) e as instituições ONU e UNICEF. Ressalta-se a importância do mesossistema famíliaescola e do macrossistema na gestão do cuidado para efetivação dos direitos humanos e da Cultura da Paz na prevenção do bullying escolar na infância.
\end{abstract}

Palavras-chave: Bullying. Violência escolar. Educação e valores. Infância e adolescência.

\begin{abstract}
The article aims to highlight human rights as an ethical statute for the prevention of school bullying in childhood in the perspective of the Culture of Peace. It is inserted in the discussion of the recognition of bullying as school violence from the conception of children of the 5th year of Teaching Fundamental about the phenomenon. The theoretical discussion is based on the dialogue between different authors such as Fante (2005), Lopes Neto (2005; 2011); Monteiro (2017), Salles Filho (2016) and the UN and UNICEF institutions. The importance of the familyschool mesosystem and the macrosystem in the management of care for the realization of human rights and of the Culture of Peace in the prevention of school bullying in childhood is highlighted.
\end{abstract}

Keywords: Bullying. School violence. Education and values. Childhood and adolescence.

"Doutoranda em Educação pela Universidade Federal do Paraná. Mestra em educação - Teoria e Prática de ensino pela Universidade Federal do Paraná. Professora da Rede Municipal de Educação de Curitiba.

** Doutora em Educação. Professora dos Programas de Pós-Graduação em Educação do Setor de Educação da Universidade Federal do Paraná 


\section{INTRODUÇÃO}

A vida em sociedade exige a relação entre indivíduos. As relações humanas são complexas e, muitas vezes, conflituosas. Por meio dos direitos humanos estas interações sociais se adequam a alguns princípios de respeito e igualdade. Estes princípios foram construídos e identificados ao longo da história humana devido às inúmeras manifestações de violência, como as guerras e conflitos mundiais, que contribuíram para a institucionalização da ONU (Organização das Nações Unidas). Com isso, formulou-se a Declaração Universal dos Direitos Humanos com o intuito de estabelecer uma relação harmoniosa entre os seres humanos. Mesmo assim, a constituição de uma sociedade harmoniosa não depende apenas dos direitos humanos, mas de indivíduos que se sensibilizem e entendam o seu papel enquanto cidadãos, e o desempenhem de forma ativa em seu meio e, por meio disso, construam e lutem pela Cultura da Paz.

Com a ascensão da ONU, os direitos humanos ganharam forças e a multiplicação e diversidade de conferências e declarações a favor da paz aumentou cada vez mais. A Declaração Universal dos Direitos Humanos, promulgada em 1948, veio como forma de garantia aos direitos dos homens e mulheres, sensibilizando em favor da paz. Por meio dela, muitas outras foram elaboradas com a intenção de institucionalizar a proteção integral da criança e do adolescente, a fim de estabelecer princípios que protejam a faixa etária, considerando que a mesma é vulnerável devido a sua peculiaridade de desenvolvimento humano. Portanto, cabe aos órgãos governamentais reconhecer e consolidar estes direitos como direito estabelecido e vigente, tornando-se não apenas ideias de uma sociedade melhor, mas uma lei universal.

A família e a escola (mesossistema) fazem parte deste círculo de proteção estabelecido para a gestão do cuidado das crianças e adolescentes. A família, como microssistema de referência da criança, garante as primeiras interações sociais e cuidados básicos. A escola, microssistema de convivência entre pares, tem por objetivo o ensino e a educação formal e também o cuidado, uma vez que reúne diversas crianças e adolescentes diferentes. Por isso, a mesma é o local de muitos conflitos, sendo um deles, o bullying escolar. Convém destacar que o bullying, não sendo um fenômeno social recente, as suas manifestações estão aumentando gradativamente nos últimos anos, trazendo preocupações aqueles que fazem parte deste microssistema.

Considerado um fenômeno sistêmico e relacional, um dos tipos de violência que envolve indivíduos e seus sistemas bioecológicos, o bullying escolar é caracterizado por ações violentas e agressivas, intencionais, repetitivas, que se manifestam entre pares, em um desequilíbrio de força e poder, sendo evidenciado no interior de muitas escolas, mostrando-se um problema real e que merece atenção. Tomando-se como base o conceito de violência de Michaud ${ }^{1}$ (1989, apud DUENHAS; GONÇALVES; GELINSKI JÚNIOR, 2014) entende-se que o bullying caracteriza-se como uma forma de violência, embora possa ser compreendido de diferentes formas em diferentes sociedades.

Neste sentido, verifica-se que as questões referentes à prevenção, na perspectiva da Cultura da Paz, precisam ser consideradas acerca dos Direitos humanos e, por isso, a escola, enquanto instituição formadora, tem em sua essencialidade a função de instruir para a convivência em sociedade. Portanto, a problemática no bullying escolar necessita de uma sensibilização e uma ação/intervenção diferenciada no sentido da prevenção, na perspectiva dos princípios da cultura da paz, para obter resultados significativos em relação aos direitos humanos da criança e do adolescente.

Diante do exposto, pode-se compreender a escola como um dos espaços de manifestações de violência, particularmente o bullying, e que a sua superação exige mudanças comportamentais e ambientais. A Bioecologia do Desenvolvimento humano propõe que, para se mudar comportamentos, mude-se o ambiente, ou seja, promova-se transições ecológicas e com elas, a qualidade das relações humanas e ambientais.

Dessa forma, tem-se por objetivo destacar os direitos humanos como estatuto ético para a prevenção do bullying escolar na infância na perspectiva da Cultura da Paz. Para isso, os dados empíricos que ilustram a pesquisa que dá suporte a este artigo, tiveram origem numa dissertação de Mestrado em Educação ${ }^{2}$ que verificou a percepção do bullying escolar em crianças do $5^{\circ}$ ano do Ensino Fundamental de uma

\footnotetext{
${ }^{1}$ MICHAUD, Y. A violência. São Paulo: Ática 1989.

${ }^{2}$ Dissertação intitulada "O bullying segundo a percepção das crianças de $5^{\circ}$ ano do ensino fundamental"
} 
escola pública da rede municipal de uma capital do sul do Brasil.

\section{METODOLOGIA}

A pesquisa descrita é de caráter qualitativo e empírico. Os estudantes participantes da pesquisa foram trinta e oito crianças do $5^{\circ}$ ano do Ensino Fundamental, entre 9 a 11 anos de idade, de ambos os sexos, do período vespertino, que atenderam o critério de inclusão para participação na pesquisa: trouxeram o TCLE (Termo de Consentimento Livre e Esclarecido) assinado pelo pai/mãe/responsável, sendo, posteriormente, observados durante as aulas e responderam a um questionário referente ao bullying, no próprio ambiente escolar, com a ciência da professora regente. Participaram dezesseis meninos e vinte e duas meninas. Para a pesquisa foi proposto um questionário semi estruturado, composto de vinte e seis perguntas. A coleta de dados foi complementada por observação participante. Os dados foram analisados a partir da Técnica de Núcleos de Significação (AGUIAR; OZELLA, 2006).

O projeto de pesquisa foi submetido ao Comitê de Ética do Setor de Ciências da Saúde da UFPR, em 10 de maio de 2016, conforme rege a legislação em Pesquisa que envolve seres humanos, em cumprimento às resoluções 466/2012 e 510/2016, da CONEP, obtendo parecer favorável $n^{\circ} 1671640$, de 10 de agosto de 2016.

Para enfatizar a importância das pesquisas sobre o bullying escolar na área educacional foi realizada uma revisão sistemática sobre o tema. A busca pelos artigos científicos que compuseram a revisão foi feita de janeiro a outubro de 2016, delimitando um período de dez anos (2005-2015) e considerando artigos somente em língua portuguesa. Foram utilizados os indexadores Scielo, PePSIC e CAPES Periódicos e as grandes áreas da Educação, Psicologia e Saúde, pelo profícuo diálogo dessas áreas do conhecimento sobre a temática, dada sua complexidade. Utilizouse os descritores Bullying, Vitimização entre pares (victimization), violência escolar (student violence) e agressão (agression) de acordo com o Thesaurus. Para realizar as combinações necessárias, usou-se o operador booleano "AND”. A primeira seleção foi feita a partir dos títulos de interesse que fossem realmente relevantes à pesquisa. Seguiu-se com a leitura dos resumos para identificar a relação explícita com a temática. Os artigos que não atenderam às recomendações dos títulos e resumos foram excluídos. Neste processo, selecionou-se trinta e um artigos de revisão para leitura completa e análise do conteúdo. Outras obras e artigos foram incluídos posteriormente (revisão de literatura), atendendo os critérios de pertinência e atualidade, durante a produção da escrita do relatório da pesquisa, pois foram relevantes para o tema (MONTEIRO, 2017).

Os artigos escolhidos mostram que o bullying tem sido pouco estudado na área da Educação, comparativamente às áreas da saúde e psicologia, demonstrando a fragilidade do tema sob o foco educacional. As hipóteses para a falta de estudos na área Educacional são: a desinformação da temática, a condição do bullying ser compreendido como "brincadeiras da idade", o discurso social das violências nas escolas, a falta de intervenções efetivas, o combate a banalização social das violências e a cultura da medicalização dos comportamentos. Estes fatores demonstram as limitações nas pesquisas sobre o bullying, no aspecto pedagógico e educacional. A busca nos indexadores revelou que apenas nove trabalhos publicados, dos trinta e um artigos escolhidos, são na área educacional.

Apesar disso, ressalta-se que houve um crescimento significativo nos estudos voltados ao bullying nos últimos anos nas áreas educacional, psicológica e médica, a partir do ano de 2009 . No entanto, mesmo havendo um aumento nos estudos sobre a temática, ainda se sente a necessidade do aprofundamento nas pesquisas em Educação. Nota-se, também, nos artigos analisados, que poucos deles são voltados ao Ensino Fundamental inicial e a percepção do estudante deste nível, frente ao bullying, mostra que poucas pesquisas dão voz e vez às crianças.

\section{BULLYING: DE QUÊ SE ESTÁ FALANDO?}

Nos sistemas ecológicos de maior relacionamento entre estudantes, em especial o microssistema escola, onde as relações afetivas e, também, as conflituosas se fazem presentes é que surge o bullying: considerado um fenômeno sistêmico, pois abrange diversas pessoas e ambientes, por meio de atitudes agressivas, premeditadas, repetitivas e entre pares. Os estudos sobre o bullying realizados nos últimos tempos por pesquisadores de vários lugares do mundo 
têm evidenciado que o fenômeno está presente no cotidiano de muitas escolas, demonstrando um problema real e grave para muitas crianças, e que ainda é sutil e velado, dificultando a identificação do mesmo.

O bullying é um fenômeno mundial que foi notado com maior intensidade na década de 70, pelo pesquisador sueco Dan Olweus, o qual iniciou suas pesquisas nesta área devido aos fenômenos de violência que estavam ocorrendo nas escolas de seu país. Ele desenvolveu os primeiros critérios para análise dos fatores que envolviam situações agressivas no ambiente escolar. No Brasil, os estudos voltados à temática iniciaram por volta dos anos 2000 com a professora doutora Cléo Fante e o pediatra Aramis Lopes Neto. Os autores chegaram à conclusão que o bullying está presente em todas as escolas, de forma mais explícita ou não, na rede pública ou privada, independente das condições sociais e econômicas das pessoas envolvidas (MONTEIRO, 2017).

A Associação Brasileira Multiprofissional de Proteção à Infância e a Adolescência (ABRAPIA) se dedica aos estudos do bullying e a sua divulgação desde 2001. Lopes Neto (2005) também realizou pesquisas juntamente com esta Associação, onde desenvolveram um projeto com duração de um ano, denominado "Redução do Comportamento Agressivo entre Estudantes". O objetivo deste projeto era investigar as principais características dos atos violentos em 5.500 estudantes entre quinta e oitava séries do Ensino Fundamental e desenvolver possíveis formas de prevenção. A pesquisa revelou índices altos de bullying dentro das escolas, com sua maior incidência nas salas de aula e a falta de orientação e de prevenção sobre a temática no ambiente escolar.

Em 2011, Moura, Cruz e Quevedo (2011) realizaram um estudo em duas escolas do estado do Rio Grande do Sul, públicas, contando com a participação de 1075 estudantes. "Este estudo teve como objetivo descrever a prevalência e as características das vítimas de bullying em duas escolas públicas" (p.20). Para a avaliação desta prevalência, os pesquisadores utilizaram um questionário denominado "Strengths and Difficulties Questionnaire” 3(SDQ) em crianças e pais. Os resultados desta pesquisa mostraram a prevalência de estudantes que sofreram bullying de 17,6\%. A maioria das agressões aconteceu no pátio da escola (55,1\%). Quanto ao tipo de intimidação, $75,1 \%$ foram verbais, $62,4 \%$ físicas, $23,8 \%$ emocionais, $6,3 \%$ racistas e $1,1 \%$ sexuais. Dentre os alvos, $47,1 \%$ revelaram já ter provocado bullying na escola e observa-se que os dados brasileiros são semelhantes aos que Dan Olweus realizou no país da Noruega.

Em 2013, os autores Oliveira-Menegotto, Pasini e Levandowski realizaram uma revisão de artigos científicos pela Universidade Federal do Rio Grande do Sul (UFRS), destacando uma pesquisa realizada com estudantes do Ensino Fundamental que mostrou a frequência que o bullying aparece na vida estudantil - " $78,8 \%$ dos alunos participantes estiveram envolvidos em atos de bullying e que as vítimas apresentam mais problemas de saúde e uma tendência quatro vezes maior para o suicídio em comparação a outros escolares" (p.207). O bullying escolar, atualmente, é considerado um dos fatores de risco que podem desencadear o suicídio em estudantes, devido ao desenvolvimento de depressão e outros sintomas psicológicos.

De acordo com as pesquisas de alguns autores brasileiros (FANTE, 2005; LOPES NETO, 2005; 2011), o Brasil ainda conta com um atraso nos estudos do bullying em relação a outros países e não possui uma vasta literatura acadêmica sobre o tema na área educacional. Além do mais, não contava com políticas públicas efetivas que auxiliassem na prevenção do bullying nas escolas. Além da Lei 13.185 que o criminaliza, a Lei $13.663 / 18$ promove medidas de "conscientização, de prevenção e de combate a todos os tipos de violência, estabelecendo ações destinadas a promover a Cultura da Paz nas escolas".

Assim, o bullying ainda se manifesta de forma velada, dificultando seu diagnóstico e compreensão. Entretanto, na escola alguns sinais são evidentes quando se deseja descobrir ações agressivas relacionadas ao fenômeno. $\mathrm{O}$ alvo de bullying sente dificuldades de concentração na aula e se distrai com muita facilidade. Suas notas caem e se sente mal toda vez que chega a segunda-feira e tem que ir à escola. Muitos estudantes inventam doenças para que fiquem em casa por mais tempo. Isso acarreta em abandono da escola e no prejuízo de seu aprendizado futuro (BEANE, 2010; FANTE, 2005). Além destes sinais, o alvo se isola de grupos e, na maioria das vezes está triste ou deprimido. Apresenta, muito comumente, hematomas, contusões, roupas rasgadas e cortes.

\footnotetext{
${ }^{3}$ Questionário sobre forças e dificuldades.
} 
Já os autores do bullying (os bullies ou os que o comete), costumam iniciar o ciclo de agressões com 'brincadeiras' de mau gosto e passam a apelidos e gozações. Usam ameaças, perturbam, intimidam, batem, beliscam, pegam materiais escolares e furtam dinheiro ou pertences. Geralmente são hostis em casa e desafiadores. Mentem com facilidade e manipulam as situações (SILVA, 2010; FANTE, 2005; LOPES NETO, 2005; 2011).

Lopes Neto (2011) sugere alguns fatores individuais e contextuais que podem gerar o bullying com mais facilidade no ambiente escolar. O gênero é o primeiro fator, quando se toma como ponto de partida as diferenças na prática do ato violento. A idade e os comportamentos individuais mostram ações observadas em diferentes faixas etárias e as diferentes atitudes relacionadas a ela. A forma como a criança se vê, a autopercepção, e a forma como percebe os outros também são fatores que podem influenciar ações agressivas na escola. Nos fatores contextuais, coloca-se o ambiente familiar e o escolar como o primeiro na escala, justamente porque são os dois microssistemas de maior convívio e influência na vida da criança. Após estes, cita o status social e a influência de amigos (outros mesossistemas e o exossistema), pois refletem a qualidade das relações. Estes fatores auxiliam na formulação de critérios no que tange ao entendimento do indivíduo e seus ambientes de convívio, bem como as condições de ocorrência do bullying na escola.

Neste fenômeno complexo de violência há três papéis fundamentais: os alvos (que podem ser típicos ou alvo/autor), os autores ou bullies e as testemunhas (observadores) (FANTE, 2005; SILVA, 2010; BEANE, 2010; LOPES NETO, 2005; BANDEIRA; HULTZ, 2010; LISBOA, BRAGA; EBERT, 2009, MONTEIRO, 2017). O alvo é aquele que sofre as agressões repetidamente e constante. Em geral, possui pouca sociabilidade, baixa autoestima e fragilidade física e emocional. O autor é o que comete a agressão contra o indivíduo mais fraco. Apresenta, na maioria dos casos, pouca empatia, caráter impulsivo, dificuldade de cumprir ordens e a necessidade de dominar. E as testemunhas são aqueles que observam e assistem as agressões, mas não se envolvem diretamente com ela. "Grande parte das testemunhas sente simpatia pelos alvos, tende a não culpá-los pelo ocorrido, condena o comportamento dos autores e deseja que os professores intervenham mais efetivamente" (LOPES NETO,
2005, p. 168). Este representa a maioria que constitui o grupo dos envolvidos que estão dentro das escolas (SILVA, 2010). O bullying é uma derrota sistêmica da escola, da família, da educação e da sociedade. Neste sentido, as consequências do bullying afetam todos os envolvidos e participantes.

Sendo o bullying uma manifestação concreta de violência, exige da escola e por parte de toda a sociedade, o seu reconhecimento, sua identificação e seu enfrentamento. Propõe-se o investimento em prevenção, entendendo-o como violação dos direitos humanos e a cultura da paz como fundamento para a prevenção na escola.

\section{RESULTADOS E DISCUSSÕES}

Os dados da pesquisa base a este artigo (MONTEIRO, 2017) trazem alguns destaques relevantes no que concerne à percepção dos estudantes de $5^{\circ}$ ano do ensino fundamental. Apesar de mostrar certo equilíbrio nas respostas entre masculino e feminino, nota-se que as meninas sentem-se mais como alvos e testemunhas do que os meninos, que se identificaram mais como autores Os dados mostram que 42,1\% dos estudantes alegam sofrer bullying na escola, o que corrobora com os estudos de Lopes Neto (2005; 2011 ) em que $40 \%$ das crianças em idade escolar sofrem agressões no contexto da escola. Ainda, os dados evidenciam que meninas sofrem bullying em maior grau que os meninos $(45,4 \%$ das meninas e $37,5 \%$ dos meninos).

Para explicar o fenômeno bullying, a Bioecologia do Desenvolvimento Humano compreende que a componente pessoa (todas aquelas que se encontram no contexto da escola) é determinante para a qualidade e quantidade de relações que estabelece nos ambientes ecológicos. A disponibilidade para a relação de qualidade é fator de proteção e prevenção do bullying na escola. Portanto, o destaque para a relevância da prática pedagógica na organização do ambiente escolar, de tal forma a promover relações interpessoais que auxiliem o desenvolvimento humano adequado para crianças é fundamental. Sendo assim, embora 57,8\% dos participantes falem que nunca sofreram bullying em seu ambiente escolar, o percentual dos que afirmaram a presença do fenômeno na escola é alto, o que mostra a importância dos estudos voltados à temática. (MONTEIRO, 2017). Bronfenbrenner (2011) 
é enfático ao afirmar que as mudanças nos ambientes são determinantes para mudanças de comportamento.

Os dados indicaram que os tipos de bullying mais utilizados, segundo as respostas dos estudantes participantes, foram o tipo verbal (89,4\% são xingamentos), na forma de apelidos, insultos ou deboches, seguidos de agressão física (chutes, socos e empurrões $-21 \%$ ). Estes dados confirmam os estudos de Bandeira e Hultz (2012) que ressaltam os xingamentos, insultos, apelidos e fofocas como as manifestações de bullying mais comuns entre os estudantes. Os meninos em geral utilizaram mais o bullying físico para agredir seus colegas, enquanto as meninas preferiram o tipo verbal. As brigas iniciam de maneira muito comum, em geral pela agressão verbal, e em muitos casos, passando para a agressão física. Schultz et. al. (2012) ressaltam que ambientes coletivos com relações violentas contribuem para as manifestações do bullying, pois "contextos com pouca possibilidade de troca e ineficazes em construir relações de negociação entre os seus membros são espaços propícios para a ocorrência do fenômeno" (p. 252).

Em relação à identificação de possíveis autores do bullying, 23,6\% dos estudantes alegaram já terem cometido agressões contra seus colegas, sendo meninas $18,1 \%$ e meninos $31,2 \%$. Os meninos se identificaram como quem mais praticou bullying, usando xingamentos ou agressões físicas contra seus colegas. Durante a ação agressiva, os alvos indicaram que a maioria das agressões são realizadas pelos meninos (86,8\%), corroborando com os estudos de Bandeira e Hultz (2012) que ressaltam o "predomínio do sexo masculino entre os agressores" (p. 42). Onze meninos se identificaram como autores de bullying e a maioria usou de xingamentos para atingir seu colega/alvo. A Bioecologia entende que mesmo os agressores (autores do bullying), considerados agentes de violência, também são fruto, em muitos casos, de um ambiente permeado de agressões, o que promove a reprodução dos padrões em outros contextos (validade ecológica), que neste caso, é a escola (MONTEIRO, 2017).

Há também aqueles que presenciam situações de bullying no ambiente escolar, denominados de testemunhas, totalizando $39,4 \%$ dos estudantes, sendo $36,3 \%$ meninas e $43,7 \%$ meninos, revelando que o fenômeno é percebido e visto na escola. Os dados também mostram que as agressões ocorrem dentro das salas de aula $(42,1 \%)$ com maior frequência. A maioria dos participantes preferem contar a um adulto a agressão que presenciaram, corroborando com a pesquisa de Bandeira e Hultz (2012), em que 60\% dos estudantes tentam ajudar seus colegas vitimizados/ alvos.

Sendo assim, apesar do movimento das pesquisas e leis que dão visibilidade ao bullying e que procuram mecanismos de sua prevenção na escola, os dados mostram certo consenso que o bullying, se faz presente nas escolas, mesmo que todos os recursos sejam utilizados, pois o comportamento agressivo sempre vai existir e se manifestar em algum momento da vida das pessoas. Fica evidente que a prevenção é o fator principal para a diminuição do fenômeno no âmbito escolar e clara necessidade do corpo de profissionais possuir capacidade técnica e habilidade específica para isso, bem como a participação da família, da sociedade e dos gestores públicos.

A própria instituição de ensino, enquanto espaço
social e político de formação e desenvolvimento
humano, precisa tomar consciência e reconhecer
a existência do fenômeno como parte da dinâmica
social (cultura de paz ainda pouco difundida, ma-
chismo, discriminação, desigualdade social, este-
reótipos, racismo, homofobia, medo, passividade e
outros comportamentos antissociais) e os prejuízos
que ele traz à vida dos seus estudantes, pessoas em
processo de desenvolvimento (MONTEIRO, 2017,
p. 47).

Concorda-se com Fante (2005) e Sacavino (2008) que as escolas precisam partir da temática voltada aos valores humanos, a ética, a moral e a cidadania, como uma forma de conscientizar as crianças e os pais/as mães sobre a importância de vivenciar a paz dentro do ambiente escolar. Cada escola deve partir de sua realidade, desenvolvendo estratégias cotidianas e contínuas. Sobre as questões éticas, ressalta-se a importância dos direitos humanos como forma de estatuto ético.

É importante ressaltar que, mesmo havendo leis, decretos e declarações que protegem a criança e o/a adolescente da violência, ainda não há o cumprimento efetivo destas políticas públicas em favor da proteção integral desta faixa etária, em especial as que vivem em situações de risco e de vulnerabilidades sociais. Dessa forma, as crianças e os/as adolescentes ainda vivem em situações inadequadas e precárias, tendo seus direitos violados por todo tipo de violência. 
O relato de muitos estudantes sobre a violência em seu ambiente escolar é diário, sendo a escola um palco para agressões constantes. O que ressalta a importância da Prevenção. Os microssistemas família e escola devem ser, indiscutivelmente, sistemas biecológicos de desenvolvimento humano pautados pelo cuidado, pela proteção e não pelas violências. É nesse cenário que o bullying ganha destaque como um fenômeno violento, entre pares, que surge na escola e que é frequente e universal, mas sempre visto como natural e normal entre os estudantes. Dar visibilidade às violências é a primeira forma de enfrentá-las. Assim, na discussão sobre o bullying e violências, a cultura da paz aparece como um pano de fundo, sendo alicerce e base para as iniciativas de prevenção do fenômeno. Portanto, a ênfase na sistematização nas relações de paz no interior das escolas, bem como o aprofundamento nesta temática é fundamental para melhorar e aprimorar os programas e projetos de minimização e de prevenção do bullying (MONTEIRO, 2017).

\section{CULTURA DA PAZ COMO PRINCÍPIO DE PREVENÇÃO EM DIREITOS HUMANOS}

As discussões efetivas sobre os direitos das crianças e adolescentes iniciaram timidamente em 1924, com um texto reconhecido internacionalmente pela Assembleia das Nações, que aprovou e endossou a formulação de um documento intitulado Declaração dos Direitos da Criança, sendo a primeira menção aos direitos humanos desta faixa etária (CONCEIÇÃO JÚNIOR; PES, 2010; BRASIL, 2013).

A Segunda Guerra Mundial (1939-1945) foi o palco de destruição, ruínas de vários países e mortes de muitas pessoas. Em abril de 1945, representantes de mais de cinquenta países se reuniram a fim de formarem um grupo internacional que fosse capaz de formular objetivos que promovessem a paz e a minimização de futuras guerras. Posteriormente, em 1948, a nova Comissão formada pelas Nações Unidas, elaborou um documento no qual declarava em seu preâmbulo os atos cruéis que conduziam os seres humanos a ações revoltantes e a esperança de um mundo em que os mesmos pudessem ser livres, libertos e dignos (CONCEIÇÃO JÚNIOR; PES, 2010; BRASIL, 2013).
Nasce então, a Declaração Universal dos Direitos humanos de 1948, proclamada pela Assembleia Geral da ONU, que definiu pela primeira vez, como um padrão comum de direitos humanos, paz e liberdade fundamentais para todos os povos e nações. Os direitos humanos são baseados nos princípios de respeito, identificando cada ser humano como ser moral e racional digno de ser tratado de forma igual. Neste sentido, os direitos humanos surgem como forma de minimização das violências. Portanto, são universais e englobam formas de opções e oportunidade para todos. Neste documento, há menção sobre os direitos da criança e do adolescente em seu art. 25, que indica a proteção integral a todo e qualquer indivíduo nesta faixa etária (CONCEIÇÃO JÚNIOR; PES, 2010; BRASIL, 2013).

Desde 1948, a ONU já adotou dezenas de declarações e de convenções sobre direitos humanos que ampliam as noções de respeito e dignidade. $\mathrm{O}$ Brasil é um dos países promotores de convenções significativas, em especial em relação às crianças e adolescentes. A evolução da temática de proteção à criança continua a ser discutida em mais um documento promulgado em 1959 e chamado de Declaração dos Direitos da Criança, realizada por meio de uma adaptação da Declaração Universal dos Direitos Humanos que contém dez princípios de dignidade, valorizando a proteção e o futuro das crianças e adolescentes (CONCEIÇÃO JÚNIOR; PES, 2010; BRASIL, 2013).

O reconhecimento de cada criança e adolescente como sujeito de direito, podendo invocar todos os direitos humanos de proteção que tocam a um adulto e outros direitos próprios dos indivíduos que estão nessa condição, somente ocorreu pela primeira vez em 1989, como marco internacional a criação da Convenção dos Direitos da Criança e, no Brasil, como marco jurídico, a Constituição de 1988, sendo que esta inclui conteúdos de proteção às crianças (artigo 277) e que teve grande influência na preparação das discussões que antecederam a citada Convenção (CONCEIÇÃO JÚNIOR; PES, 2010; BRASIL, 2013).

A Convenção sobre Direitos das Crianças de 1989 é considerada um dos seis documentos de maior importância da ONU. Este documento abrange todas as áreas que envolvem os direitos humanos como civis, políticos, econômicos, sociais e culturais, reafirmando juntamente o conteúdo da Declaração 
Universal dos Direitos Humanos de 1948, ressaltando a política de proteção integral infantil, em seu art. 25, "todas as crianças, nascidas dentro ou fora de matrimônio, gozarão da mesma proteção social”.

O fator de proteção integral ganha destaque uma vez que se justifica pela prioridade de cuidados especiais a pessoas (crianças e adolescentes) em situação de desenvolvimento, e por isso, vulneráveis. Além deste fator, a desigualdade social leva muitos a viverem em situações graves de sobrevivência, o que implica na marginalização, colocando as crianças e adolescentes como vítimas da omissão e da negligência da família, do Estado e da sociedade em geral. As vulnerabilidades que atingem as crianças são, em geral, as relacionadas a conflitos e violência familiar, bem como a vulnerabilidade social decorrente da cultura das desigualdades que predomina no país. A condição de moradia, oferta dos serviços públicos, relações sociais violentas e de risco como o envolvimento com drogas, trabalho infantil e exploração sexual de crianças também as afetam e as tornam mais vulneráveis. Então, as vulnerabilidades são manifestadas por meio de consequências na vida das crianças, em seus contextos de maior vivência: a família e a escola (ABRAMOVAY; LIMA; VARELLA, 2003; ROMERO, 2009; BRASIL, 2013; SALLES FILHO, 2016).

Partindo do pressuposto da proteção integral da criança e do adolescente, cabe enfatizar a importância, não só das leis e documentos que, juridicamente, cuidam destes indivíduos, mas o dever da família e da escola no papel da gestão do cuidado. Desde o momento do seu nascimento, a criança interage com o ambiente, com as pessoas e com as coisas ao seu redor e isto continua ao longo de sua vida. Inicialmente, as primeiras interações ocorrem com pessoas de seu convívio e ambientes familiares, nos microssistemas família. Conforme crescem, estas interações se ampliam e novas situações são introduzidas nela, aumentando o nível de relações sociais (sistemas bioecológicos). Assim, a criança passará por mudanças no desenvolvimento a partir das contribuições de pessoas e do próprio ambiente que ali estiverem envolvidas com ela. Juntas, estas transições ecológicas ${ }^{4}$ contribuirão para agregar valores, ideias, crenças e hábitos. Portanto,

\footnotetext{
${ }^{4}$ Transição do indivíduo entre os microssistemas por meio das interações, consolidando relações positivas ou negativas.
}

são nos microssistemas que as crianças vivenciam suas experiências, interagindo com novas pessoas e novos ambientes e evidenciam seu desenvolvimento humano. Pode-se assim afirmar, que família e escola são dois contextos importantes para o desenvolvimento da criança (BRONFENBRENNER, 2011; DINIZ; KOLLER, 2010).

A proteção integral foi efetivada com o Estatuto da Criança e do Adolescente (ECA), no ano de 1990, adotando regulamentações mais avançadas em relação à criança e ao adolescente, ressaltando mais uma vez a ênfase pelos direitos humanos nestas faixas etárias, sendo um avanço na questão da tutela do Estado. Portanto, os direitos das crianças e adolescentes tem por fundamento a dignidade humana, não apenas por serem uma parcela da sociedade considerada vulnerável, mas porque são direitos inerentes a todo e qualquer ser humano (CONCEIÇÃO JÚNIOR; PES, 2010; BRASIL, 2013).

No Brasil, além da família e da escola, a responsabilidade das prefeituras (instâncias de governo mais próximas da população) em relação à proteção integral das crianças abrange a prevenção e o enfrentamento das violências, promovendo o cumprimento dos direitos humanos da criança e do adolescente. Neste sentido, as prefeituras podem e devem atuar, contribuindo para a sensibilização da população e diretamente no enfrentamento das violências, por meio da informação, prevenção, atendimento, enfretamento dos casos, articulação e capacitação. As situações precisam ser notificadas para que se possa assegurar a proteção e defesa dos direitos. Por isso, existem os Conselhos Tutelares, responsáveis na atuação e encaminhamento das denúncias. $\mathrm{O}$ atendimento não só envolve a punição do responsável pela violência, mas também no acompanhamento da criança ou do adolescente, adotando as medidas de proteção necessárias (UNICEF, 2005).

Cultura da paz é um termo muito utilizado na área educacional atualmente, trazendo noções de valores como respeito e altruísmo. É um conjunto de atitudes e valores com a intenção de prevenção das violências e conflitos por meio do diálogo entre pares. "Como Cultura de Paz entende-se o grande campo de atividades humanas que levem em conta um mundo melhor, mais humano, mais feliz e sustentável. Assim, a Cultura de Paz vale para todos os seres humanos" (SALLES FILHO, 2016, p. 140). 
As pesquisas mostram que o bullying é uma realidade concreta, presente nas escolas e que interfere significativamente no comportamento dos estudantes, bem como de seus familiares, durante período importante do ciclo vital. Neste sentido, é importante ressaltar a prevenção do bullying como investimento no campo da saúde mental, com resultados na vida educacional e social de crianças e adolescentes.

Cabe enfatizar que o conceito de prevenção encontra sustentação nos princípios da Cultura da Paz, pois há ênfase na mudança de comportamentos individuais e na forma como se organiza metodologicamente os ambientes escolares (clima escolar) para promoverem a paz, uma vez que auxilia nas relações humanas e na própria prevenção. Essa construção dá visibilidade ao processo de efetivação dos direitos humanos, dando vida e dinamicidade a eles. A Cultura da Paz e os direitos humanos estão permeados de valores, princípios essenciais para o processo de humanização, necessários a formação e desenvolvimento, em especial a crianças e adolescentes.

Estes valores são atribuídos ao ser humano por meio de ações concretas, atuando de forma a melhorar seu comportamento e suas relações com outro indivíduos e mundo, assim como na influência no nível macro, atuando na modificação de processos sociais, políticas públicas e programas educacionais que transmitam valores relacionados à paz. Em contrapartida, tais mudanças não são fáceis justamente porque o que se vê na sociedade atual é o oposto a tudo isso: a violência conduzindo muitas atitudes sociais e relacionais entre as pessoas de diversas formas e em diferentes níveis.

Para se construir a paz é necessário adquirir novas atitudes que valorizem os princípios do coletivo, novas formas de relacionamento baseados na empatia e respeito, assim como a necessidade do aprofundamento da diversidade, cooperação e diálogo. O reconhecimento de si e do outro como sujeitos de direitos, a capacidade de tolerância na mediação de conflitos, a convivência entre pares, respeitando a diversidade e o desenvolvimento da cooperação em grupo são eixos fundamentais para se promover o bom relacionamento entre os indivíduos, e consequentemente, promover a paz e a efetivação dos direitos humanos. Por isso, a importância da construção também do conceito de "Educação para a Paz" com a intenção de trazer para dentro das escolas ações pedagógicas que visem às formas de prevenção e mudanças cotidianas, sempre dimensionando a estrutura social e cultural (SACAVINO, 2008; SACAVINO; CANDAU, 2012; PROJETO JUVENTUDE E PREVENÇÃO DA VIOLÊNCIA, 2010; UNESCO, 2010; SALLES FILHO, 2016).

Para isso, cabe ao ser humano ter a sua responsabilidade diante da sociedade, atuando com a sua participação enquanto cidadão, tendo como pano de fundo a tolerância, a mobilização, a conscientização e o cumprimento dos direitos humanos - respeitando o próximo e dando o devido valor aos princípios da cultura de paz - esta iniciativa é de longo prazo, leva em conta todo um contexto histórico, social e cultural de um povo, uma sociedade, uma nação. "A paz é um processo constante, cotidiano, mas não passivo. A humanidade deve esforçar-se para promovê-la e administrá-la" (UNESCO, 2010, p. 15). A violência gerada nas escolas é um problema de ordem social e cultural e por isso a importância de uma mudança de mentalidade do ser humano. A educação é a chave que liga essa conquista da paz às escolas.

Uma das formas de mudança de comportamento, frente as violências na escola, em especial o bullying escolar, na perspectiva da Cultura da Paz, é o que propõe a Justiça Restaurativa, envolvendo todos os personagens relacionados. "Quando bem sucedido, este procedimento transforma uma relação marcada pela oposição e violência, em relação cooperativa, partindo das pessoas concretas, suas necessidades e o dano sofrido". (BOONEN, 2016, p. 266). A Justiça Restaurativa é uma ação/intervenção que permite o diálogo entre saberes, em especial, da educação com os campos antropológico, político, filosófico e psicológico.

Assim, ao se pensar na escola como ambiente permeado por relações entre pares, que manifestam valores e crenças para o ser humano, não há como compreender a prevenção sem antes entender o indivíduo e suas particularidades. Por isso, a necessidade do trabalho de pontos relevantes do estudante para se efetivamente assimilar o bullying e sua forma de manifestação nas escolas, assim como as formas mais adequadas e eficazes para preveni-lo. As situações de bullying precisam ser eliminadas de forma construtiva, envolvendo a valorização dos direitos, da diversidade, do pluralismo e das relações sociais estabelecidas na escola, pois todos podem ser agentes da construção da 
cultura de paz. A cultura da Paz caracteriza-se como uma epistemologia e uma metodologia para fundamentar a prevenção do bullying, ancorada nos direitos humanos.

\section{CONSIDERAÇÕES FINAIS}

A educação para paz é um processo educativo importante para a promoção e construção de valores e conceitos éticos cidadãos que podem ser estabelecidos juntamente aos conteúdos disciplinares da escola. A educação para a paz é o processo que possibilita a Cultura da Paz na escola. Sem dúvida, os valores como respeito e empatia são fundamentais para a formação de comportamentos generosos e solidários. Este processo de valorização dos direitos humanos e do respeito ao próximo é uma forma de prevenção ao bullying, bem como a toda e qualquer forma de violência manifestada no ambiente escolar. Por isso, a importância do estabelecimento de mecanismos que promovam estas questões no espaço escolar.

Sendo assim, não se pode negar as relações que se estabelecem entre o bullying, os valores e os direitos humanos, uma vez que a sociedade entende a violência como construção social e tende a naturalizar as ações agressivas como ditas normais. Há uma tendência social em justificar algumas situações de violência como brincadeiras infantis, postergando ainda mais a identificação do fenômeno no ambiente escolar. Neste sentido, a escola e a sociedade precisam identificar as raízes culturais do bullying, revendo seus conceitos e valores, estabelecendo assim, metas para prevenção. Evidencia-se que, embora os direitos humanos estejam estabelecidos há mais de setenta anos, ainda não estão totalmente incorporados como direitos efetivos da sociedade, determinantes dos projetos e programas de prevenção das escolas, bem como princípios das famílias. Tendo em vista os dados mostrados neste artigo sobre o bullying escolar, os direitos humanos precisam ser relembrados como dotados de valores que devem permear todas as decisões humanas, em especial no que concerne a infância e adolescência. A educação precisa ser em direitos humanos e na perspectiva da Cultura da Paz.

Neste princípio, a construção da Cultura da Paz se dará por meio do diálogo e da compreensão de pressupostos que se contrapõem à violência, com o intuito de se compreender o real sentido do conflito social.
Pensar em questões da violência estrutural e social que atingem a sociedade, sucumbindo os direitos humanos das pessoas e compreendidas como dominação do mais fraco pelo mais forte são fundamentais para a formação de uma base sólida do conceito de paz e de prevenção na sociedade, que surgem a partir da compreensão do que é são as violências e como elas se manifestam.

A necessidade de criação de novas políticas públicas e da adequação à realidade das escolas brasileiras acerca das que já existem é fundamental, ao passo que elas podem promover ambientes melhores para o desenvolvimento humano. O investimento na capacitação dos profissionais da educação para identificação e reconhecimento do bullying no ambiente escolar, para que as intervenções ocorram de maneira mais efetiva, são mecanismos que auxiliam, bem como a presença e apoio da família na vida dos estudantes. Pensando por um viés preventivo, pode-se pensar em trabalhos com a autoestima dos estudantes, visto como um fator de proteção ou de risco para o desencadeamento de sentimentos de vitimização, os relacionamentos entre pares e aceitação de si.

\section{REFERÊNCIAS}

ABRAMOVAY, Miriam; LIMA, Fabiano; VARELLA, Santiago. Percepções dos alunos sobre as repercussões da violência nos estudos e na interação social na escola. In: (org.). Escola e violência. Brasília: UNESCO, UCB, p. 89$117,2003$.

AGUIAR, Wanda Maria Junqueira; OZELLA, Sérgio. Núcleos de Significação como instrumento para a apreensão da constituição dos sentidos. Psicologia, Ciência e Educação. v. 26. n. 2, p. 222-245, 2006.

BANDEIRA, Cláudia de Moraes. Bullying: autoestima e diferenças de gênero. 2009, 69 f. Dissertação (Mestrado em Psicologia). Departamento de Psicologia, Universidade Federal do Rio Grande do Sul, Porto Alegre, 2009.

; HUTZ, Claudio Simon. As implicações do bullying na autoestima dos adolescentes. Revista Semestral da Associação Brasileira de Psicologia Escolar e Educacional. São Paulo. v. 14. n. 1, p. 131-138, jan/jun. 2010.

BEANE, Allan. Proteja seu filho do bullying. Tradução: Débora Guimarães Isidoro. Rio de Janeiro: Best Seller, 2010.

BOONEN, Petronella Maria. O lugar do perdão na Justiça Restaurativa. UEPG Appl. Soc. Sci, Ponta Grossa, v. 24, n. 3, 
set./dez. 2016. Disponível em: http://www.revistas2.uepg. br/index.php/sociais. Acesso em: 28 mai. 2018.

BRASIL, Constituição (1988). Constituição. República Federativa do Brasil. Brasília, 1988.

Convenção dos direitos da criança. República Federativa do Brasil. Brasília, 1959.

Estatuto da Criança e do Adolescente. Estatuto da criança e do adolescente. República Federativa do Brasil. Brasília, 1990.

Lei $\mathrm{n}^{\circ} 13.185$, de 6 de novembro de 2015. Portal da Legislação. Disponível em: http://www.planalto.gov.br/ ccivil_03/_Ato2015-2018/2015/Lei/L13185.htm. Acesso em: 19 out. 2016.

Portal Brasil. MEC, Brasília, 2015. Disponível em: http://www.brasil.gov.br/governo/2015/11/presidentadilma-sanciona-lei-de-combate-ao-bullying. Acesso em: ago. 2015 .

Secretaria de Direitos Humanos da Presidência da República. Educação em Direitos Humanos: Diretrizes Nacionais. Brasília, 2013.

BRONFENBRENNER, Urie. Bioecologia do desenvolvimento humano: tornando os seres humanos mais humanos. Tradução: André de Carvalho Barreto. Porto Alegre: Artmed, 2011.

DECLARAÇÃO dos direitos humanos. Disponível em: $<$ http: www.onu-brasil.org.br / documentos _direitos humanos. php>. Acesso em: 28 mai. 2018.

DINIZ, Eva; KOLLER, Silvia Helena. O afeto como processo do desenvolvimento ecológico. Educar em Revista. Curitiba. n. 36, p. 65-76, jan. 2010.

DUENHAS, Rogério Allon; GONÇALVES, Flávio de Oliveira; GELINSKI JÚNIOR, Eduardo. Educação, segurança pública e violência nos municípios brasileiros: uma análise de painel dinâmico de dados. UEPG Ci. Soc. Apl, Ponta Grossa, v. 22, n. 2, p. 179 - 191, jul./ dez. 2014. Disponível em http://www.revistas2.uepg.br/index.php/ sociais. Acesso em: 28 mai. 2018.

FANTE, Cléo. Fenômeno bullying: como prevenir a violência nas escolas e educar para a paz. Campinas: Verus, 2005.

CONCEIÇÃO JÚNIOR, Hermes Siedler; PES, João Hélio Ferreira. Os direitos das crianças e adolescentes no contexto histórico dos direitos humanos. In: PES, João Hélio Ferreira (coord.). Direitos Humanos: Crianças e adolescentes. Curitiba: Juruá, 2010.

LISBOA, Carolina; BRAGA, Luiza de Lima; EBERT, Guilherme. O fenômeno Bullying ou vitimização entre pares na atualidade: definições, formas de manifestação e possibilidades de intervenção. Contextos Clínicos. v. 2 n. 1 , p. 59-71, jan/jun. 2009.
LOPES, Ana Christina Brito. (Org). Proteção integral de crianças e adolescentes: instrumentos normativos nacionais e internacionais. Estatuto da criança e do adolescente. 2.ed. Curitiba, PR: SECS, 2015.

LOPES NETO, Aramis Antônio. Bullying - comportamento agressivo entre estudantes. Jornal de Pediatra. Rio de Janeiro, v. 81 n. 5 p. 164-175, 2005.

Bullying: saber identificar e como prevenir. São Paulo: Brasiliense, 2011.

MOURA, Danilo Rolim de; CRUZ, Ana Catarina Nova; QUEVEDO, Luciana de Ávila. Prevalência e características de escolares vítimas de bullying. Jornal de Pediatria. v. 87. n. 1, p. 19-23, 2011.

MONTEIRO, Michelle Popenga Geraim; RIBEIRO, Everton; ASINELLI-LUZ, Araci. Reflexões sobre o bullying escolar e a perspectiva de gênero: a percepção de crianças do quinto ano do ensino fundamental. In: SIMPÓSIO INTERNACIONAL DE EDUCAÇÃO SEXUAL. 5. 2017, Maringá. Anais. Maringá: UEM, p. 1-15, 2017.

MONTEIRO, Michelle Popenga Geraim. O bullying segundo a percepção dos estudantes do $5^{\circ}$ ano do ensino fundamental. 2017, 148 f. Dissertação (Mestrado em Educação) - Setor de Educação, Universidade Federal do Paraná, Curitiba, 2017.

OLIVEIRA-MENEGOTTO, Lisiane Machado de; PASINI, Audri Inês; LEVANDOWSKI, Gabriel. O bullying escolar no Brasil: uma revisão de artigos científicos. Psicologia: Teoria e Prática. São Paulo. v. 15. n. 2, p. 203-215, mai/ ago. 2013.

PREVENÇÃO da violência entre adolescentes e jovens no brasil: estratégias de atuação. Instituto Sou da Paz: Ministério da justiça. Brasília, 2010.

ROMERO, Emilio. Vulnerabilidade Humana e conflitos sociais: suas fontes. In: ROMERO, Emilio; RIBEIRO, Wânier (org). Vulnerabilidade humana e conflitos sociais: para uma psicologia social compreensiva existencial. São Paulo: Della Bídia, 2009.

SACAVINO, Susana. Educação para paz e a não-violência: formação em serviço de professores/as. In: SACAVINO, Susana; CANDAU, Vera Maria. Educação em Direitos Humanos: temas, questões e propostas. Petrópolis: Alli, 2008.

CANDAU, Vera Maria. Educação em Direitos Humanos e bullying: oficinas para enfrentamento e prevenção. Rio de Janeiro: Novamerica, 2012.

SALLES FILHO, Nei Alberto. Cultura de paz, violência, conflitos e condição de pobreza: aproximações conceituais e implicações sociais. In: SIMPÓSIO INTERNACIONAL INTERDISCIPLINAR EM CIÊNCIAS SOCIAIS APLICADAS. 1. 2016, Ponta Grossa. Anais. Ponta Grossa: UEPG, p. 1-14, 2016. 
- Pedagogia dos direitos

humanos no contexto da educação para a paz: elementos a partir dos estudos de Johan Galtung. In: CONGRESSO DE DIREITOS HUMANOS E POLÍTICAS PÚBLICAS. 2016, Curitiba. Anais. Curitiba: PUCPR, 2016.

SCHULTZ, Naiane Carvalho Wendt; DUQUE, Denise Franco; SILVA, Carolina Fermino da; SOUZA, Carolina Duarte de; ASSINI, Luciana Cristina; CARNEIRO, Maria da Glória de. A compreensão sistêmica do bullying. Psicologia em Estudo. Maringá. v. 17. n. 2, p. 247-254, abr/jun. 2012.

SILVA, Ana Beatriz Barbosa da. Mentes perigosas nas escolas: bullying. Rio de Janeiro: Objetiva, 2010.

UNESCO. Cultura de paz: da reflexão à ação; balanço da Década Internacional da Promoção da Cultura de Paz e Não Violência em Benefício das Crianças do Mundo. Brasília: UNESCO. São Paulo: Associação Palas Athena, 256 p, 2010.

School violence and Bullying: global status report. Brasília, 2017.

UNICEF. O município e a criança de até 6 anos: direitos cumpridos, respeitados e protegidos. Brasília: UNICEF, 2005. 